\section{Homocysteine, folates, and the eye}

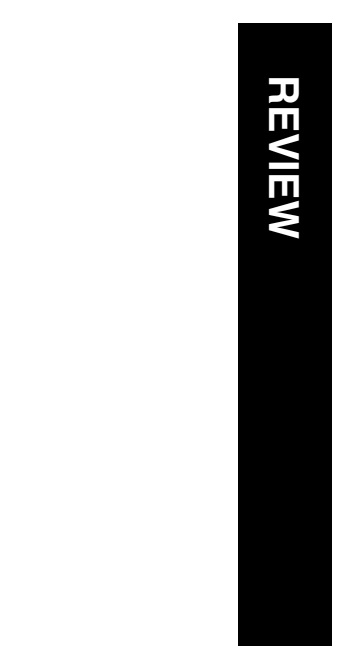

\begin{abstract}
Plasma homocysteine has been identified as a risk factor for arterial disease, retinal artery and vein occlusions, and other common eye diseases. The value of treating an elevated plasma homocysteine with folic acid for preventing further vascular disease has not been proven. Although secondary prevention of coronary artery disease using this approach has been unsuccessful, trials on primary prevention of stroke and loss of cognitive function with folic acid supplementation appear to be successful. Further trial data are awaited. In patients with premature retinovascular disease, the measurement of plasma homocysteine is suggested and reduction of elevated homocysteine with folic acid for secondary prevention of retinal arterial and venous occlusion. Meanwhile, the debate on fortification of flour for primary prevention of neural tube defects, which has already taken place in North America, continues in European countries. Such fortification could have an impact on primary and secondary prevention of vascular disease. Eye (2008) 22, 989-993; doi:10.1038/sj.eye.6703061; published online 7 December 2007
\end{abstract}

Keywords: homocysteine; folic acid; arterial disease; retinal artery and vein occlusions

\section{Introduction}

Considerable interest and research in homocysteine metabolism has evolved following the findings of atherosclerotic plaques in young people with homocysteinuria. ${ }^{1}$ Arterial and venous thromboses are common in such patients. Since then, homocysteinaemia has been identified in the general population as an independent risk factor for cardiovascular disease. ${ }^{2}$ Furthermore, plasma homocysteine levels can be reduced by folic acid, vitamin $B_{12}$, and vitamin $B_{6}$. This survey will, therefore, highlight the possible contribution that homocysteine makes to the pathogenesis of
AD Wright, N Martin and PM Dodson

ocular problems, with particular emphasis on vascular diseases, and will review the results from recent trials of folic acid supplementation in primary and secondary prevention of cardioand cerebrovascular disease.

\section{Homocysteine and vitamins}

Hyperhomocyteinaemia has several causes (Table 1) including dietary deficiencies of the vitamin cofactors (folates, vitamin $\mathrm{B}_{12}$, and vitamin $B_{6}$ ) required for the metabolism of homocysteine, and functional polymorphisms of the genes encoding for enzymes affecting homocysteine metabolism (methylenetetrahydrofolate reductase, cystathione $\beta$ synthase, and methionine synthase). A review of methods of measurement of plasma levels of homocysteine is available. ${ }^{3}$ Methods should be standardised as far as possible by taking a fasting venous blood sample and separating the plasma without delay. Homocysteine circulates mostly as sulphides, which are complexed with albumin. Reduction of these bonds with dithiothreitol and protein precipitation is required before measurement by high-pressure liquid chromatography. ${ }^{4}$ More recently, attempts have been made to develop automated methods. ${ }^{5}$

Folates are water-soluble B-complex vitamins important in single-carbon transfers in the metabolism of amino acids and nucleic acids. Naturally occurring folates are found in most foods, particularly in liver, kidney, green vegetables, beans, nuts, and fruits but are heatlabile and partly removed from food during storage and preparation. The daily intake of folate is about $0.2 \mathrm{mg}$ in northern European countries. The recommended dietary allowance varies from country to country, but in the United States, it is $0.4 \mathrm{mg}$ a day. Folic acid is the form used in vitamin supplementation and in fortified food products, and doses up to $0.8 \mathrm{mg}$ daily reduce plasma homocysteine concentrations by about $25 \%$, but no further reduction on using higher doses. It is probably important to distinguish between physiological
Department

Ophthalmology,

Birmingham Heartlands

Hospital, Birmingham, UK

Correspondence: P Dodson, Department Birmingham Heartlands Hospital,

Birmingham B9 5SS, UK

Tel: + 44121424 2104;

Fax: + 441214240593 .

E-mail: paul.dodson@

heartofengland.nhs.uk

Received: 9 February 2007 Accepted in revised form: 10 November 2007

The authors are not in receipt of any grants to support this work. The audit of homocyteine in retinal vein occlusion has been presented at a meeting of the Medical Ophthalmological Society.
Ophthalmology, Published online:

7 December 2007 
Table 1 Causes of hyperhomocysteinaemia

\begin{tabular}{ll}
\hline $\begin{array}{l}\text { Genetic factors } \\
\text { Polymorphisms of } \\
\text { methylenetetrahydrofolate }\end{array}$ & $\begin{array}{c}\text { Other epidemiological factors } \\
\text { Male gender }\end{array}$ \\
$\begin{array}{l}\text { reductase } \\
\text { Polymorphisms of } \\
\text { cystathionine } \beta \text { synthase } \\
\text { Polymorphisms of methionine } \\
\text { synthase }\end{array}$ & $\begin{array}{l}\text { Post-menopause } \\
\text { Smoking }\end{array}$ \\
& \\
Nutritional factors & \\
Folate deficiency & Chronic diseases \\
Vitamin $\mathrm{B}_{6}$ deficiency & Renal impairment \\
Vitamin $\mathrm{B}_{12}$ deficiency & Diabetes mellitus \\
Excessive intake of methionine & Hypothyroidism \\
Alcoholism & Psoriasis \\
& Cancer \\
& Organ transplantation \\
\hline
\end{tabular}

doses of folic acid $<1 \mathrm{mg}$ daily for primary prevention in healthy people and pharmacological doses of folic acid $>1 \mathrm{mg}$ daily used in the management of anaemia.

Vitamin $\mathrm{B}_{12}$ supplementation using at least $0.4 \mathrm{mg}$ daily reduces plasma homocysteine by about $7 \%$ and vitamin $B_{6}$ also has an effect. Vitamin $B_{12}$ is probably a more important determinant of increased plasma homocysteine in older people than folate, and vitamin $\mathrm{B}_{12}$ becomes the limiting nutrient for the maintenance of normal plasma concentrations, once folate levels are optimised. The potential side effects of folic acid supplementation include the masking of vitamin $B_{12}$ deficiency and the precipitation of neurological complications, the alteration of the effectiveness of certain medications such as phenytoin and anti-folate drugs, cancer promotion, and the rates of twin pregnancies. The relationship of folates and cancer is complex, as folate deficiency seems to predispose normal epithelial tissues to neoplastic transformation but folate supplementation promotes progression of established tumours. Monitoring of cancer incidence following the introduction of any large-scale folic acid supplementation in the community is therefore important.

\section{Homocysteine and eye disease}

Many eye problems occur in homocysteinuria with subluxation of the lens, myopia, cataracts, cystic retinal degeneration, and retinal detachment. Central retinal artery occlusion and retinal haemorrhages have been reported, but not retinal vein occlusion.

\section{Venous and arterial occlusions}

A detailed meta-analysis of studies of 614 patients in 10 studies of retinal vascular occlusive disease showed significantly elevated plasma levels of homocysteine in central retinal vein occlusion, branch retinal vein occlusion, and retinal artery occlusion when compared with controls. ${ }^{6}$ In only one study, plasma homocysteine levels were lower in cases compared with controls. We have shown that increased plasma homocysteine is associated with both retinal vein occlusion and retinal arterial occlusion, the elevation being greater in the arterial occlusion group. ${ }^{7}$ In young patients, retinal vein occlusion is less associated with systemic diseases ${ }^{8}$ and is more strongly associated with plasma homocysteine than in older patients. ${ }^{9}$

In a recent audit of 17 patients $<55$ years of age presenting with a retinal vein occlusion, we found elevated plasma homocysteine in 35\%, although this was rarely as an isolated finding. Patients with retinal vein occlusion are more likely to die from a cardiovascular event than those without an occlusion, and the feared complication, unlike retinal artery occlusion, is recurrence of venous occlusion in the fellow eye. The serious risk of recurrent retinal vein occlusion, recorded as $11.9 \%$ at 4 years in the fellow eye, ${ }^{10}$ underpins the policy of aggressive management of all contributing risk factors. What is not clear is whether an elevated plasma homocysteine level should be lowered in a patient with retinovascular disease. Data from the large treatment trials of cardio- and cerebro-vascular disease may help with this decision. Studies of retinal vein occlusion have not shown any association with plasma vitamin $B_{12}$ concentrations or with methylenetetrahydrofolate reductase genotype polymorphisms.

\section{Diabetic retinopathy}

A relationship of plasma homocysteine and diabetic retinopathy has been shown in many ${ }^{11-14}$ but not all studies. ${ }^{15}$ It is doubtful whether plasma homocysteine is an independent variable for diabetic retinopathy, as several reports suggest that any rise is secondary to renal disease and renal failure, which is often associated with diabetic nephropathy and thus with retinopathy. ${ }^{16}$

\section{Glaucoma, age-related macular degeneration, and cataract}

The role of homocysteine in other eye conditions is less clear. Increased plasma homocysteine has been reported in pseudo-exfoliative ${ }^{17,18}$ but not in primary angle glaucoma. ${ }^{19}$ Studies have shown increased plasma homocysteine in patients with age-related macular degeneration. ${ }^{20,21}$ Another study showed that there were no differences in plasma homocysteine or folate concentrations in those with exudative compared with dry age-related macular degeneration ${ }^{22}$ although it was 
of interest that plasma vitamin $\mathrm{B}_{12}$ levels were lower in the exudative group. Good nutrition appears to protect against age-related nuclear lens opacities but there is no direct evidence that folic acid intake is independently linked. ${ }^{23}$ These data, therefore, suggest that homocysteine levels have no clear relationship with these common eye problems.

\section{Homocysteine and vascular disease}

Atherosclerotic plaques occur in young people with homocysteinuria who suffer from premature, aggressive arterial, and, in addition, venous occlusive disease. Plasma concentrations of homocysteine are an independent risk factor for cardiovascular and cerebrovascular disease in the general population. ${ }^{24}$ Dementia and the risk of developing dementia are also associated with homocysteinaemia. Animal studies have suggested that the mechanism of this relationship is that homocysteine causes increased oxidative stress with vascular endothelial damage and enhances thrombogenicity. Whether homocysteine is the cause or merely a marker of vascular disease is not known. All these observations have led to the hypothesis that homocysteine may cause or contribute to atherosclerosis. Indeed, there is a graded association between plasma levels of homocysteine and cardiovascular risk. Calculations from epidemiological studies suggest that a $3 \mathrm{mmol} / 1$ decrease in plasma homocysteine, which is achievable by supplementation with $0.8 \mathrm{mg}$ folic acid daily, would produce a $15 \%$ reduction in ischaemic heart disease risk and $24 \%$ in stroke.

Folic acid $0.8 \mathrm{mg}$ daily has been suggested as one of the ingredients of the polypill, which, on recent calculation, can reduce cardiovascular disease by more than $80 \% .^{25}$ However, clinical trials based on the reduction of plasma concentrations of plasma homocysteine have not consistently prevented vascular disease (Table 2$)^{26,27}$ and have not supported this calculation. The modest effects of folic acid supplementation mean that large numbers are needed in clinical trials and more than 2-year duration of therapy is required. Naturally, the

Table 2 Meta-analysis of randomised, controlled, secondary prevention trials of folic acid supplementation

\begin{tabular}{lccc}
\hline & \multicolumn{2}{c}{ No. of events/total } & $\begin{array}{c}\text { Pooled relative } \\
\text { risk }(95 \% \text { CI })\end{array}$ \\
\cline { 2 - 3 } & Folic acid & Control & \\
\hline Cardiovascular disease & $1420 / 7755$ & $1286 / 6685$ & $0.95(0.99-1.03)$ \\
Coronary heart disease & $1022 / 8962$ & $840 / 7915$ & $1.04(0.92-1.17)$ \\
Stroke & $352 / 7432$ & $370 / 6374$ & $0.86(0.71-1.04)$ \\
All-cause mortality & $960 / 8020$ & $861 / 6975$ & $0.96(0.99-1.04)$ \\
\hline
\end{tabular}

effectiveness of folic acid supplementation will be determined by the overall intake of folates in that population. However, overall trial data of secondary prevention are consistent with a $12 \%$ reduction in ischaemic heart disease and a $22 \%$ reduction in stroke. Further study results, for example SEARCH in ischaemic heart disease and VITATOPS in stroke, are awaited.

For other vascular problems, folic acid supplementation has not shown any beneficial effects, as for example in peripheral vascular disease ${ }^{28}$ and in reducing the risk of symptomatic venous thromboembolism. $^{29}$

\section{Primary prevention}

There is little data on the use of folic acid in primary prevention of ocular diseases but there is a suggestion from epidemiological studies that a high folate intake and also vitamin $B_{12}$ supplements may be protective against the development of nuclear cataract. ${ }^{30}$ Data on primary prevention of cardiovascular disease and folic acid supplementation are limited. However, the ongoing Folic Acid and Carotid Intimal Thickness (FACIT) trial has reported significant improvements in cognitive function in subjects aged 50-70 years with baseline elevation of plasma homocysteine concentrations ${ }^{31}$ and a useful meta-analysis of eight randomised trials of folic acid supplementation showed reduction in the risk of stroke by $18 \% .^{32}$ This meta-analysis found a greater beneficial effect if the treatment was for more than 36 months and if plasma homocysteine concentrations were reduced by more than $20 \%$. More information on the primary prevention of cardiovascular disease is needed and it would appear that cardiac disease should be studied separately from cerebral disease.

\section{Public health issues}

Meanwhile, the main public health debate on folic acid supplementation in the general population is based on its importance in reproduction and the prevention of neural tube defects rather than vascular disease. Several public health measures increase folate levels including the encouragement of healthy eating of vegetables and wholemeal products, voluntary or mandatory fortification of food with folic acid, or supplementary folic acid tablets. Women in the UK who are trying to conceive are advised to take supplementary folic acid $0.4 \mathrm{mg}$ daily up to 12 weeks gestation. Voluntary fortification of food with folic acid practised in UK and several other member states in the European Union makes a useful contribution but does not achieve the recommended daily intake of $0.4 \mathrm{mg}$. Compulsory fortification of cereal grain in North 
America (0.14 mg folic acid per $100 \mathrm{~g}$ ) since 1998 has resulted in an increase in the mean daily intake of $0.19 \mathrm{mg}$ folic acid and a decrease in plasma homocysteine by 7\%. In Canada, neural-tube defects have been reduced by $40 \% .{ }^{33}$ The Food Standards Agency is reviewing its position on whether fortification of flour with folic acid should become mandatory in the UK. ${ }^{34}$ In the meantime, a vigorous debate on the subject has outlined all the issues involved. ${ }^{35}$ Those in favour of fortification claim that such a policy reaches people who are less well off and who have the most to gain from prevention of neural-tube defects, cleft lip, dementia, and possibly cardiovascular disease with no increase in cancer risk. Those against fortification stress the possibility of the cancer-promoting effects of exposure to folic acid in susceptible people. Although it will be difficult to measure the effect that such fortification will have on the long-term development of vascular disease and eye diseases, all the information to date would suggest that it would be modestly beneficial.

\section{Conclusions}

The role of homocysteine in eye disease is complex. Observational studies have shown that several eye conditions in the general population, such as some forms of glaucoma and age-related macular degeneration, are associated with raised plasma homocysteine concentrations. Raised plasma concentrations of homocysteine in diabetic retinopathy may be secondary to renal disease. There is a clear relationship of raised plasma concentrations of homocysteine, retinal vein, and artery occlusions.

Evidence from controlled trials for any benefit from reduction of homocysteine is limited. It is possible that the risk of stroke can be reduced. Trials of folic acid for secondary prevention of ocular disease such as retinal vein occlusion would be difficult because of the numbers needed to treat. For patients with retinal vein occlusion, extrapolation from results in stroke and dementia prevention may be the best evidence available. The effect of any increase in folate intake in the general population as a result of mandatory fortification of flour with folic acid will also be a confounding factor. In the meantime, while the outcomes of further large, randomised trials are awaited, we would recommend measurement of fasting plasma homocysteine in younger patients with retinal vein or artery occlusion, and in other patients with premature vascular disease. The use of folic acid supplementation if hyperhomocystinaemia is identified in these situations is not based on firm evidence but the results from stroke prevention are encouraging.

\section{References}

1 McCully KS. Vascular pathology of homocysteinuria: implications for the pathogenesis of arteriosclerosis. Am J Pathol 1969; 56: 111-128.

2 Wald DS, Law M, Morris JK. Homocysteine and cardiovascular disease; evidence of causality from a metaanalysis. BMJ 2002; 325: 1202-1206.

3 Maron BA, Loscalzo J. Homocysteine. Clin Lab Med 2006; 26: 591-609.

4 Martin SC, Tsakas-Ampatzia I, Bartlett WA, Jones AF. Measurement of plasma homocysteine by HPLC with coulometric detection. Clin Chem 1999; 45: 150-152.

5 Zappacosta B, Persichilli S, Minucci A, Scribano D, Antenucci M, Fasanella $S$ et al. Analytical evaluation of a new immunononephelmetric method for homocysteine measurement. Clin Chim Acta 2007; 375: 165-168.

6 Cahill MT, Stinett SS, Fekrat S. A meta-analysis of plasma homocysteine, serum folate, serum B12 and thermolabile MTHFR genotype as risk factors for retinal vascular occlusive disease. Am J Ophthalmol 2003; 136: 1136-1150.

7 Martin SC, Rauz S, Marr JE, Martin N, Jones AF, Dodson PM. Plasma total homocysteine and retinal vascular disease. Eye 2000; 14: 590-593.

8 Fong ACO, Schatz H. Central retinal vein occlusion in young adults. J Ophthalmol 1993; 37: 393-417.

9 Chua B, Kifley A, Wong TY, Mitchell P. Homocysteine and retinal vein occlusion: a population-based study. $A m \mathrm{~J}$ Ophthalmol 2005; 139: 181-182.

10 Hayreh SS, Zimmerman MB, Podhaisky P. Incidence of various types of retinal vein occlusion and their recurrence and demographic characteristics. Am J Ophthalmol 1994; 117: 429-441.

11 Looker HC, Fagot CA, Gunter EW, Pfeiffer CM, Narayan KMV, Knowler WC et al. Homocysteine as a risk factor for nephropathy and retinopathy in Type 2 diabetes. Diabetologia 2003; 46: 766-772.

12 Vaccaro O, Ingrosso D, Rivellese A, Greco G, Riccardi G. Moderate hyperhomocysteinemia and retinopathy in insulin-dependent diabetes. Lancet 1997; 349: 1102-1103.

13 Goldstein M, Leibovitch I, Yeffimov I, Gavendo S, Sela BA, Loewenstein A. Hyperhomocysteinemia in patients with diabetes mellitus with and without retinopathy. Eye 2004; 18: $460-465$.

14 Huang EJ, Khu WW, Chen YJ, Chen TH, Chang M, $\mathrm{Lu} \mathrm{MC}$ et al. Homocysteine and other biochemical parameters in Type 2 diabetes mellitus with different diabetic duration or diabetic retinopathy. Clin Chim Acta 2006; 366: 293-298.

15 Yuecel I, Yeucel G, Mueftueoglu F. Plasma homocysteine levels in noninsulin-dependent diabetes mellitus with retinopathy and neovascular glaucoma. Int Ophthalmol 2004; 25: 201-205.

16 Soedamah MSS, Chaturvedi N, Teerlink T, Idzior WR, Fuller $\mathrm{JH}$, Stehouwer CDA. Plasma homocysteine and microvascular and macrovascular complications in type 1 diabetes: a cross-sectional nested case control study. J Intern Med 2005; 258: 450-459.

17 Vessani RM, Ritch R, Liebmann JM, Jofe M. Plasma homocysteine is elevated in patients with exfoliation syndrome. Am J Ophthalmol 2003; 136: 41-46.

18 Leibevitch I, Kurtz S, Shemesh S, Goldstein M, Sela BA, Lazar $\mathrm{M}$ et al. Hyperhomocysteinemia in psuedoexfoliation glaucoma. J Glaucoma 2003; 12: 36-39. 
19 Wang G, Medeiros F, Barshop BA, Weinreb RN. Total plasma homocysteine and primary open-angle glaucoma. Am J Ophthalmol 2004; 137: 401-406.

20 Coral K, Raman R, Rathi S, Rajesh M, Sulochana KN, Angayarkanni $\mathrm{N}$ et al. Plasma homocysteine and total thiol content in patients with exudative age-related macular degeneration age-related macular degeneration. Eye 2006; 20: 203-207.

21 Axer-Siegel R, Bourla D, Ehrlich R, Dotan G, Benjamin Y, Gavendo $S$ et al. Association of neovascular age-related macular degeneration and homocysteinemia. Am J Ophthalmol 2004; 137: 84-89.

22 Kamburoglu G, Gumus K, Kadayifcilar S, Eldem B. Plasma homocusteine, vitamin B12 and folate levels in age-related macular degeneration. Graefes Arch Clin Exp Ophthalmol 2006; 24: 565-569.

23 Jacques PF, Chylack LT, Hankinson SE, Khu PM, Rogers G, Friend $\mathrm{J}$ et al. Long-term nutrient intake and early agerelated nuclear lens opacities. Arch Ophthalmol 2001; 119: 1009-1019.

24 The Homocysteine Studies Collaboration. Homocysteine and risk of ischemic heart disease and stroke: a metaanalysis. J Am Med Assoc 2002; 288: 2015-2022.

25 Wald NJ, Law M. A strategy to reduce to reduce cardiovascular disease by more than $80 \%$. BMJ 2003; 326: 1419.

26 Loscalzo J. Homocysteine trials - clear outcomes for complex reasons. N Engl J Med 2006; 354: 1629-1632.

27 Bazzano LA, Reynolds K, Holder KN, He J. Effect of folic acid supplementation on risk of cardiovascular diseases.
A meta-analysis of randomized controlled trials. J Am Med Assoc 2006; 296: 2720-2726.

28 Schernthaner GH, Plank C, Minar E, Biegimayer C, Koppensteiner R, Schernthaner G. No effect of homocysteine-lowering therapy on vascular inflammation and maemostasis in peripheral arterial occlusive disease. Eur J Clin Invest 2006; 26: 333-339.

29 Ray JG, Kearon C, Yi Q, Sheridan P, Lonn E. Homocysteine lowering therapy and risk for venous thromboembolism: a randomized trial. Ann Int Med 2007; 146: 761-767.

30 Kuzniarz M, Mitchell P, Cumming RG, Flood VM. Use of vitamin supplements and cataract: the blue mountain eye study. Am J Ophthalmol 2001; 132: 19-26.

31 Durga J, van Boxtel MP, Schouten EG, Kok FJ, Jolles J, Katan $\mathrm{MB}$ et al. Effect of 3-year folic acid supplementation on cognitive function in older adults in the FACIT trial: a randomised, double blind, controlled trial. Lancet 2007; 369: 208-216.

32 Wang X, Qin X, Demirtas H, Li J, Mao G, Huo G et al. Efficacy of folic acid supplementation in stroke prevention: a meta-analysis. Lancet 2007; 369: 1876-1882.

33 de Wals P, Tairou F, van Allen MI, Uh SH, Lowry RB, Sibbald B et al. Reduction in neural tube defects after folic acid fortification in Canada. N Engl J Med 2007; 357: 135-142.

34 Eichholzer M, Tonz O, Zimmermann R. Folic acid: a public health challenge. Lancet 2006; 367: 1352-1361.

35 Wald NJ, Oakley GP, Hubner RA, Houlston RD, Muir KR. Should folic acid fortification be mandatory? BMJ 2007; 334 : 1252-1253. 